\title{
Impact of COVID-19 on utilization of nonpharmacological and pharmacological treatments for chronic low back pain and clinical outcomes
}

https://doi.org/10.1515/jom-2020-0334

Received December 31, 2020; accepted March 2, 2021; published online March 29, 2021

\begin{abstract}
Context: The novel coronavirus 2019 (COVID-19) pandemic has impacted the delivery of health care services throughout the United States, including those for patients with chronic pain.

Objectives: To measure changes in patients' utilization of nonpharmacological and pharmacological treatments for chronic low back pain and related outcomes during the COVID-19 pandemic.

Methods: A pre-post study was conducted within the Pain Registry for Epidemiological, Clinical, and Interventional Studies and Innovation (PRECISION Pain Research Registry) using data in the 3 months before and 3-6 months after the declaration of a national emergency related to COVID-19. Participants 21-79 years old with chronic low back pain were included in the study and provided self reported data at relevant quarterly encounters. Use of exercise therapy, yoga, massage therapy, spinal manipulation, acupuncture, cognitive behavioral therapy, nonsteroidal antiinflammatory drugs, and opioids for low back pain was measured. The primary outcomes were low back pain intensity and back related functioning measured with a numerical rating scale and the Roland Morris Disability Questionnaire, respectively. Secondary outcomes included health related quality of life scales measured with the Patient Reported Outcomes Measurement Information System, including scales for physical function, anxiety, depression, low energy/fatigue, sleep
\end{abstract}

*Corresponding author: John C. Licciardone, DO, MS, MBA, Regents Professor, The Osteopathic Research Center and the Department of Family Medicine, University of North Texas Health Science Center, Texas College of Osteopathic Medicine, 3500 Camp Bowie Boulevard, Fort Worth, TX 76107, USA, E-mail: john.licciardone@unthsc.edu disturbance, participation in social roles and activities, and pain interference with activities.

Results: A total of 476 participants were included in this study. The mean age of participants at baseline was 54.0 years (standard deviation, \pm 13.2 years; range, $22-81$ years). There were 349 (73.3\%) female participants and 127 (26.7\%) male participants in the study. Utilization of exercise therapy (odds ratio [OR], 0.37; 95\% confidence interval [CI], 0.23-0.57), massage therapy (OR, 0.46; 95\% CI, 0.25-0.83), and spinal manipulation (OR, 0.53; 95\% CI, 0.29-0.93) decreased during the pandemic. A reduction in NSAID use was also observed (OR, 0.67; 95\% CI, 0.45-0.99). Participants reported a significant, but not clinically relevant, improvement in low back pain intensity during the pandemic (mean improvement, 0.19; 95\% CI, 0.03-0.34; Cohen's $d, 0.11)$. However, White participants reported a significant improvement in low back pain intensity (mean improvement, 0.28; 95\% CI, 0.10-0.46), whereas Black participants did not (mean improvement, -0.13; 95\% CI, -0.46 to 0.19; $p$ for interaction $=0.03$ ). Overall, there was a significant and clinically relevant improvement in pain interference with activities (mean improvement, 1.11; 95\% CI, 0.20-2.02; Cohen's $d, 0.20$ ). The use of NSAIDs during the pandemic was associated with marginal increases in low back pain intensity.

Conclusions: Overall, decreased utilization of treatments for chronic low back pain did not adversely impact pain and functioning outcomes during the first 6 months of the pandemic. However, Black participants experienced significantly worse pain outcomes than their White counterparts.

Keywords: chronic low back pain; COVID-19; nonpharmacological therapy; opioids; pain management.

Low back pain is highly prevalent and is the leading cause of disability worldwide [1]. A transition from acute to chronic low back pain is often accompanied by disability, which may be associated with higher patient utilization of invasive procedures and greater health care expenditures. 
National guidelines [2,3] recommend nonpharmacological treatments as first line interventions to manage chronic low back pain before it becomes disabling. However, the impact of the COVID-19 pandemic on chronic low back pain management and related clinical outcomes in the United States remains unclear, as we remain in the midst of a pandemic that was first declared a national emergency in the United States on March 13, 2020 [4].

An international expert panel issued consensus recommendations [5] for chronic pain management during the early stage of the pandemic that included using telemedicine first and exclusively in most cases. Another expert panel consisting of leaders from the Veterans Health Administration, United States military, medical societies, and academia similarly recommended that telemedicine be utilized whenever possible if indicated for pain management [6]. However, telemedicine carries both benefits and drawbacks in managing chronic pain. Although telemedicine may improve access to health care during the pandemic, there may be patient engagement issues, diminished quality of interaction between providers and patients, and limited ability to perform a physical examination or intervention [7]. Moreover, the growth over time in utilization of mobile technologies to facilitate the physical modalities and psychology based therapies that may be most applicable to chronic low back pain management has yielded only small and questionable clinical benefits [6].

There is emerging evidence that the uptake of several nonpharmacological treatments was significantly impacted by lockdowns or social distancing restrictions imposed within the 3 months immediately following the national emergency proclamation, although low back pain intensity and back related functioning appeared unaffected [8]. The purpose of this study was to use a pain research registry to update measures of the utilization of first line treatments for chronic low back pain and related clinical outcomes as the pandemic now extends into 2021 in the United States.

\section{Methods}

Study participants were selected from the Pain Registry for Epidemiological, Clinical, and Interventional Studies and Innovation (PRECISION Pain Research Registry). When the registry was established at the University of North Texas Health Science Center in 2016, participants were primarily recruited from its clinics and other local health care facilities in the Dallas-Fort Worth metroplex using either face-to-face or online screening questionnaires for eligibility. The registry transitioned to a digital research platform in 2019, thereby facilitating remote screening and the subsequent collection of data on chronic low back pain management and outcomes from eligible participants throughout the 48 contiguous states and District of Columbia. Such remote data acquisition ensured the ongoing operations of the registry without interruption during the COVID-19 pandemic, thereby enabling the present study to be conducted. The registry enrolls participants with chronic low back pain according to the National Institutes of Health diagnostic criteria [9]. These require that participants report having had low back pain for at least the past 3-6 months, and with a frequency of at least half of the days over the past 6 months. Registry participants must range from 21 to 79 years old at enrollment and be able to complete case report forms in English, either independently or with assistance from registry staff. Registry procedures were approved by the North Texas Regional Institutional Review Board (protocol 2015-169) and all study participants provided written informed consent prior to enrollment.

Registry participants completed case report forms at quarterly intervals. They provided responses to the following at each quarterly encounter: items within the Minimum Dataset for Chronic Low Back Pain recommended by the National Institutes of Health [9]; a current treatments inventory involving the utilization of six common nonpharmacological treatments (exercise therapy, yoga, massage therapy, spinal manipulation, acupuncture, and cognitive behavioral therapy), nonsteroidal antiinflammatory drugs (NSAIDs), and opioids for low back pain; an 11 point numerical rating scale (NRS) for low back pain intensity (0-10); and the Roland Morris Disability Questionnaire for back related functioning (0-24) [10]. Participants also provided responses to various other research instruments, including a comorbidity history inventory involving nine common spinal or medical conditions (herniated disc, sciatica, osteoporosis, osteoarthritis, hypertension, heart disease, diabetes mellitus, asthma, and depression), the Patient Reported Outcomes Measurement Information System with 29 items (PROMIS-29) [11], Pain Catastrophizing Scale [12], and Pain Self Efficacy Questionnaire [13] upon enrollment and during other scheduled quarterly encounters. This study included registry participants who reported standard quarterly encounter data during the 3 months immediately prior to the national emergency proclamation date relating to the COVID-19 pandemic (December 2019 through March 2020) and who also reported the corresponding paired data during the quarterly encounter that occurred from 3 to 6 months after the national emergency proclamation date (June 2020 through September 2020).

Descriptive statistics were used to summarize participant characteristics, including the mean \pm standard deviation for continuous variables and the number (\%) for categorical variables. The impact of the pandemic on utilization of each nonpharmacological and pharmacological treatment for low back pain was analyzed using McNemar's test for the paired observations for each participant during the relevant quarterly encounters prior to the national emergency proclamation date and during the pandemic. Correspondingly, paired changes on the NRS for low back pain intensity and on the Roland Morris Disability Questionnaire for back related functioning reported by each participant during the relevant quarterly encounters were analyzed using the Student's t-test to assess these primary clinical outcomes. Paired changes reported by participants on the PROMIS-29 for health related quality of life during these quarterly encounters were considered secondary clinical outcomes because this instrument was not deployed at all quarterly registry encounters, thereby yielding smaller sample sizes and diminished statistical power in these analyses. Subgroup analyses involving 13 prespecified demographic, clinical, and psychological variables were also conducted for the primary clinical outcomes to test for interaction effects. Finally, linear regression was used to assess the relationships between utilization of each nonpharmacological and pharmacological treatment and primary clinical outcomes during the pandemic from June 2020 through 
September 2020. These regression analyses included a series of univariate models and a multivariate model for each primary clinical outcome. Participant data were recoded as needed for certain clinical outcomes so that all measures reported herein as positive change scores represent improvements during the pandemic, whereas negative change scores represent worsening. Cohen's $d$ statistic was computed for the paired t-test results to assess the effect of the pandemic on each clinical outcome measure (small effect, $0.20 \leq d \leq 0.49$; medium effect, $0.50 \leq d \leq 0.79$; large effect, $d \geq 0.80$ ) [14], in addition to conventional statistical significance testing. Any outcome not meeting the threshold for at least a small effect was considered not clinically relevant. Data management and statistical analyses were primarily performed with the IBM SPSS Statistics software package (Version 25). Two sided tests and significance thresholds of $\mathrm{p} \leq 0.05$ were used for all statistical analyses.

\section{Results}

A total of 476 registry participants provided paired data for the relevant study periods prior to and during the COVID-19 pandemic. The mean age of participants at baseline was 54.0 years (standard deviation, \pm 13.2 years; range, $22-81$ years). There were 349 (73.3\%) female participants and 127 (26.7\%) male participants in the study (Table 1). A total of 216 (45.4\%) participants reported ever having lost work for at least 1 month, and 115 (24.2\%) participants had ever received disability or workers' compensation benefits because of their low back pain. The mean number of comorbid conditions was $2.8 \pm 1.8$ and 246 (51.7\%) participants reported depression. Mean NRS scores for low back pain intensity and RMDQ scores for back related functioning were $6.1 \pm 2.0$ and $14.3 \pm 6.4$, respectively. Participants reported deficits across the entire spectrum of health related quality of life on the PROMIS-29 instrument, particularly in the domains of physical function (mean, $37.5 \pm 7.3$ ) and pain interference with activities (mean, $63.6 \pm 7.5$ ).

The utilization of nonpharmacological treatments for low back pain decreased during the pandemic. The mean number of nonpharmacological treatments used by participants between December 2019 and March 2020 was $0.68 \pm 1.00$ compared with $0.47 \pm 0.85$ for the period from June 2020 through September 2020 ( $\mathrm{p}<0.001)$. There were significant reductions in the use of exercise therapy (OR, 0.37; 95\% CI, 0.23-0.57; $\mathrm{p}<0.001$ ), massage therapy (OR, 0.46 ; 95\% CI, $0.25-0.83 ; \mathrm{p}=0.008$ ), and spinal manipulation (OR, 0.53; 95\% CI, 0.29-0.93; $\mathrm{p}=0.03$; Table 2). The use of NSAIDs for low back pain also decreased significantly (OR, 0.67 ; 95\% CI, 0.45-0.99; $\mathrm{p}=0.045$ ), whereas opioid use remained unchanged (OR, 1.00; 95\% CI, 0.58-1.73; $>$ >0.99).

The distributions of improvement in low back pain intensity and back related functioning during the pandemic
Table 1: Participant characteristics during the pre-COVID-19 pandemic period $(n=476)$.*

\begin{tabular}{|c|c|}
\hline Characteristic & n (\%) \\
\hline \multicolumn{2}{|l|}{ Sociodemographic } \\
\hline Age, years, mean \pm SD (range) & $\begin{array}{r}54.0 \pm 13.2 \\
(22-81)\end{array}$ \\
\hline \multicolumn{2}{|l|}{ Sex } \\
\hline Male & $127(26.7)$ \\
\hline Female & $349(73.3)$ \\
\hline \multicolumn{2}{|l|}{ Race } \\
\hline American Indian or Alaskan native & $7(1.5)$ \\
\hline Asian & $6(1.3)$ \\
\hline Black & $105(22.1)$ \\
\hline Native Hawaiian or other Pacific Islander & $3(0.6)$ \\
\hline White & $355(74.6)$ \\
\hline \multicolumn{2}{|l|}{ Ethnicity } \\
\hline Hispanic & $59(12.4)$ \\
\hline NonHispanic & $417(87.6)$ \\
\hline \multicolumn{2}{|l|}{ Ever had work loss $\geq 1$ month due to LBP } \\
\hline Yes & $216(45.4)$ \\
\hline No & $260(54.6)$ \\
\hline \multicolumn{2}{|l|}{$\begin{array}{l}\text { Ever received disability or workers' } \\
\text { compensation benefits due to LBP }\end{array}$} \\
\hline Yes & $115(24.2)$ \\
\hline No & $361(75.8)$ \\
\hline \multicolumn{2}{|l|}{ Comorbidity history ${ }^{a}$} \\
\hline Herniated disc & $166(34.9)$ \\
\hline Sciatica & $202(42.4)$ \\
\hline Osteoporosis & $57(12.0)$ \\
\hline Osteoarthritis & $183(38.4)$ \\
\hline Hypertension & $202(42.4)$ \\
\hline Heart disease & $48(10.1)$ \\
\hline Diabetes mellitus & $97(20.4)$ \\
\hline Asthma & $133(27.9)$ \\
\hline Depression & $246(51.7)$ \\
\hline \multicolumn{2}{|l|}{ Clinical } \\
\hline Current smoker & $71(14.9)$ \\
\hline Current widespread pain & $122(25.6)$ \\
\hline Ever had LBP surgery & $87(18.3)$ \\
\hline $\mathrm{BMI}, \mathrm{kg} / \mathrm{m}^{2}$, mean $\pm \mathrm{SD}$ (range) & $\begin{array}{r}32.5 \pm 8.2 \\
(16-65)\end{array}$ \\
\hline PCS score, mean \pm SD $(\text { range })^{\mathrm{a}}$ & $\begin{array}{r}19.6 \pm 13.8 \\
(0-52)\end{array}$ \\
\hline 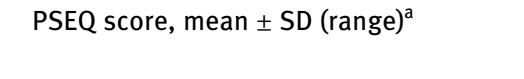 & $\begin{array}{r}33.9 \pm 15.0 \\
(0-60)\end{array}$ \\
\hline NRS score, mean \pm SD (range) & $\begin{array}{r}6.1 \pm 2.0 \\
(1-10)\end{array}$ \\
\hline RMDQ score, mean \pm SD (range) & $\begin{array}{r}14.3 \pm 6.4 \\
(0-24)\end{array}$ \\
\hline \multicolumn{2}{|l|}{ Health related quality of life (PROMIS-29) } \\
\hline Physical function, mean \pm SD (range) & $\begin{array}{r}37.5 \pm 7.3 \\
(22.9-56.9)\end{array}$ \\
\hline Anxiety, mean \pm SD (range) & $\begin{array}{l}56.8 \pm 10.5 \\
(40.3-81.6)\end{array}$ \\
\hline Depression, mean \pm SD (range) & $\begin{array}{r}54.7 \pm 9.9 \\
(41.0-79.4)\end{array}$ \\
\hline Low energy/fatigue, mean \pm SD (range) & $\begin{array}{l}59.6 \pm 10.8 \\
(33.7-75.8)\end{array}$ \\
\hline
\end{tabular}


Table 1: (continued)

\begin{tabular}{lr}
\hline Characteristic & $\mathbf{n}(\%)$ \\
\hline Sleep disturbance, mean \pm SD (range) & $57.4 \pm 8.7$ \\
& $(32.0-73.3)$ \\
Participation in social roles and activities, mean \pm SD & $43.2 \pm 9.3$ \\
(range) & $(27.5-64.2)$ \\
Pain interference with activities, mean \pm SD (range) & $63.6 \pm 7.5$ \\
& $(41.6-75.6)$
\end{tabular}

*Table entries are $\mathrm{n}(\%)$ unless otherwise indicated. ${ }^{\mathrm{a}}$ Data were

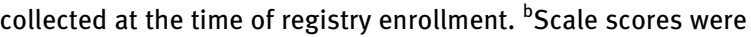
normed to the United States general population, with mean $\pm S D=50 \pm 10$. Higher scores represent worse quality of life on all scales except physical function and participation in social roles and activities. These data were available for 230 participants during the pre-COVID-19 period because the PROMIS-29 instrument was not deployed at all quarterly registry encounters. BMI, body mass index; COVID-19, novel coronavirus 2019; LBP, low back pain; NRS, Numerical Rating Scale for low back pain intensity; PCS, Pain Catastrophizing Scale; PROMIS-29, Patient Reported Outcomes Measurement Information System with 29 items; PSEQ, Pain Self Efficacy Questionnaire; RMDQ, Roland Morris Disability Questionnaire for back related functioning; SD, standard deviation.

are presented in Figure 1. Participants reported significant improvement in low back pain intensity during the pandemic (mean NRS score improvement, 0.19; 95\% CI, 0.03-0.34; $p=0.02$; Table 3). However, the magnitude of low back pain improvement (Cohen's $d=0.11$ ) was not considered to be clinically relevant. Back related functioning was essentially unchanged during the pandemic (mean RMDQ score improvement, $-0.01 ; 95 \% \mathrm{CI},-0.33$ to $0.31 ; \mathrm{p}=0.95$ ). In subgroup analyses, White participants reported significant improvement in low back pain intensity (mean improvement, 0.28; 95\% CI, 0.10-0.46), whereas Black participants did not (mean improvement, $-0.13 ; 95 \% \mathrm{CI},-0.46$ to 0.19 ) (p for interaction $=0.03$; Table 4). Overall, participants reported a significant improvement in the degree to which pain interfered with their activities on the PROMIS-29 instrument (mean score improvement, 1.11; 95\% CI, 0.20-2.02; $\mathrm{p}=0.02$ ), which met the threshold for a small effect (Cohen's $d=0.20$ ). None of the other secondary clinical outcomes for health related quality of life achieved statistical significance or clinical relevance.

A marginally significant negative association was observed for the use of NSAIDs in the linear regression models for improvement in low back pain intensity, including the model that adjusted for age, sex, and use of each of the other nonpharmacological and pharmacological treatments (standardized $\beta$ coefficient, $-0.094 ; t,-2.04 ; \mathrm{p}=0.04$; Table 5). There were no other significant associations involving age, sex, or use of any other nonpharmacological or pharmacological treatments in the linear regression models for improvement in low back pain intensity or improvement in back related functioning.

\section{Discussion}

The number of nonpharmacological treatments for chronic low back pain used by participants in this study decreased significantly during the initial 6 months of the COVID-19 pandemic. Specifically, participants were less likely to report using exercise therapy, massage therapy, and spinal manipulation. The latter finding has potentially important implications for osteopathic physicians, if patients with low back pain are less likely to visit them for osteopathic manipulative treatment during the pandemic because of

Table 2: Utilization of nonpharmacological and pharmacological treatments for chronic low back pain before and during the COVID-19 pandemic $(n=476)$.*

\begin{tabular}{|c|c|c|c|c|c|}
\hline Treatment & $\begin{array}{r}\text { Pre-COVID-19 pandemic } \\
\text { (Dec } 2019 \text { to Mar 2020) } \\
n(\%)\end{array}$ & $\begin{array}{r}\text { During COVID-19 pandemic } \\
\text { (Jun } 2020 \text { to Sep 2020) } \\
n(\%)\end{array}$ & OR & $95 \% \mathrm{Cl}$ & p-value \\
\hline \multicolumn{6}{|l|}{ Nonpharmacological } \\
\hline Exercise therapy & $89(18.7)$ & $42(8.8)$ & 0.37 & $0.23-0.57$ & $<0.001$ \\
\hline Yoga & $43(9.0)$ & $38(8.0)$ & 0.78 & $0.40-1.52$ & 0.53 \\
\hline Massage therapy & $71(14.9)$ & $50(10.5)$ & 0.46 & $0.25-0.83$ & 0.008 \\
\hline Spinal manipulation & $85(17.9)$ & $67(14.1)$ & 0.53 & $0.29-0.93$ & 0.03 \\
\hline Acupuncture & $11(2.3)$ & $7(1.5)$ & 0.50 & $0.11-1.87$ & 0.39 \\
\hline Cognitive behavioral therapy & $25(5.3)$ & $21(4.4)$ & 0.75 & $0.32-1.69$ & 0.57 \\
\hline \multicolumn{6}{|l|}{ Pharmacological } \\
\hline Nonsteroidal antiinflammatory drugs & $300(63.0)$ & $278(58.4)$ & 0.67 & $0.45-0.99$ & 0.045 \\
\hline Opioids & $150(31.5)$ & $150(31.5)$ & 1.00 & $0.58-1.73$ & $>0.99$ \\
\hline
\end{tabular}

*The use of each treatment during the COVID-19 pandemic relative to the prepandemic period was measured by the OR, based on McNemar's test. Cl, confidence interval; COVID-19, novel coronavirus 2019; OR, odds ratio. 

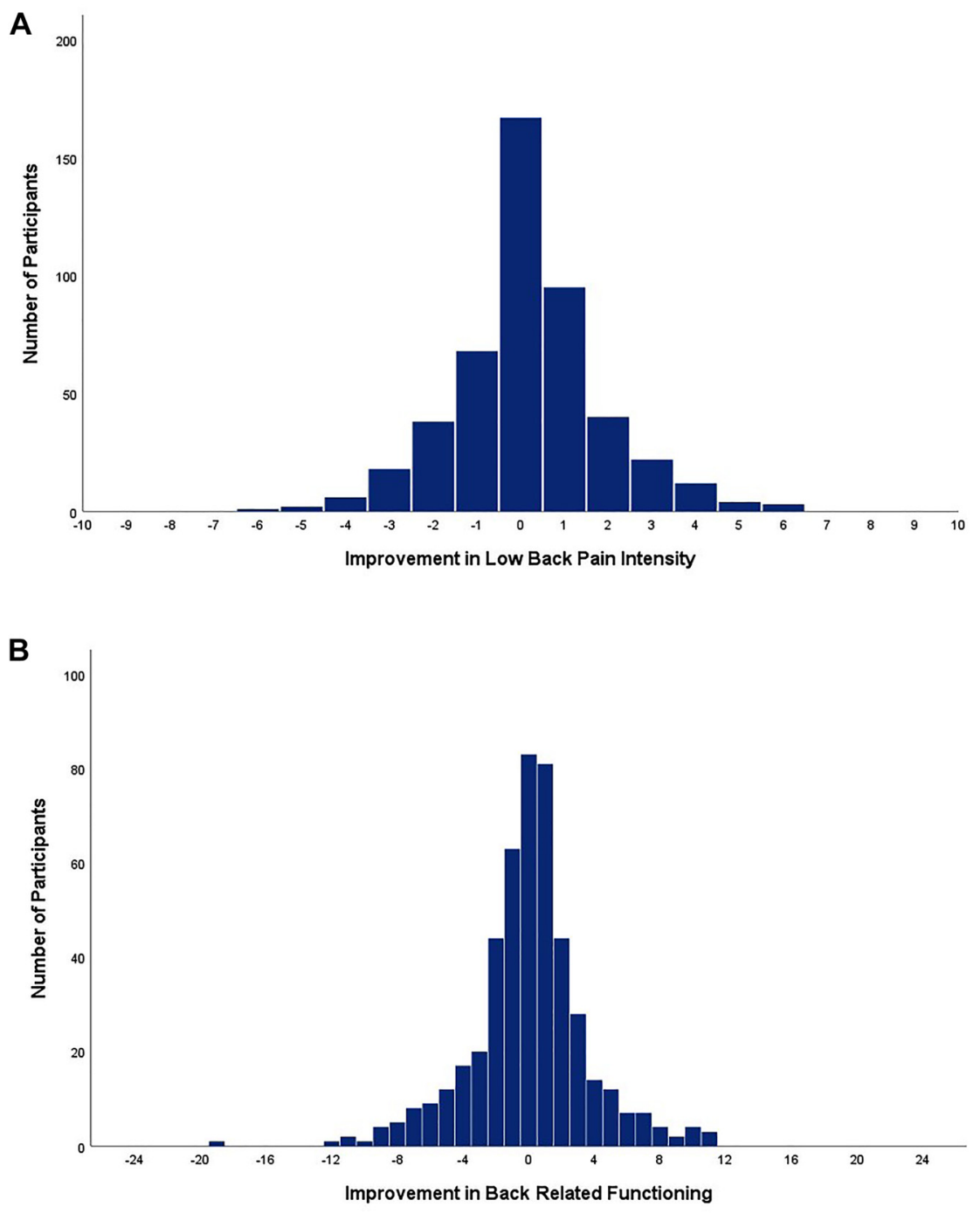

Figure 1: Distributions of improvements in (A) low back pain intensity and (B) back related functioning during the novel coronavirus 2019 (COVID-19) pandemic. Improvements were computed as change scores reported by participants on a numerical rating scale for low back pain intensity and the Roland Morris disability questionnaire for back related functioning from the period prior to the pandemic (December 2019 to March 2020) to the period during the pandemic (June 2020 to September 2020). Positive values represent improvement.

Table 3: Improvement in clinical outcomes during the COVID-19 pandemic.*

\begin{tabular}{|c|c|c|c|c|c|}
\hline Improvement measure & n & Mean & $95 \% \mathrm{Cl}$ & Cohen's $d$ & p-value \\
\hline \multicolumn{6}{|l|}{$\begin{array}{l}\text { Primary clinical } \\
\text { outcomes }\end{array}$} \\
\hline Low back pain intensity & 476 & 0.19 & $0.03-0.34$ & 0.11 & 0.02 \\
\hline Back related functioning & 476 & -0.01 & $-0.33-0.31$ & 0.00 & 0.95 \\
\hline \multicolumn{6}{|l|}{$\begin{array}{l}\text { Secondary clinical } \\
\text { outcomes }^{\mathrm{a}}\end{array}$} \\
\hline Physical function & 147 & 0.37 & $-0.26-0.99$ & 0.10 & 0.25 \\
\hline Anxiety & 147 & -0.15 & $-1.50-1.21$ & -0.02 & 0.83 \\
\hline Depression & 147 & 0.32 & $-0.83-1.47$ & 0.04 & 0.59 \\
\hline Low energy/fatigue & 147 & 0.71 & $-0.51-1.93$ & 0.10 & 0.25 \\
\hline Sleep disturbance & 147 & -0.47 & $-1.64-0.70$ & -0.07 & 0.42 \\
\hline Participation in social roles and activities & 147 & 0.29 & $-0.72-1.31$ & 0.05 & 0.57 \\
\hline Pain interference with activities & 147 & 1.11 & $0.20-2.02$ & 0.20 & 0.02 \\
\hline
\end{tabular}

*Low back pain intensity was measured with an 11 point numerical rating scale. Back related functioning was measured with the Roland Morris Disability Questionnaire. Secondary clinical outcomes were measured with the Patient Reported Outcomes Measurement Information System with 29 items. ${ }^{\text {T}}$ The number of paired observations for the secondary clinical outcomes was smaller because the PROMIS-29 instrument was not deployed at all quarterly registry encounters. Cl, confidence interval; COVID-19, novel coronavirus 2019. 
Table 4: Subgroup analyses for improvement in primary clinical outcomes during the COVID-19 pandemic.*

\begin{tabular}{|c|c|c|c|c|c|c|c|c|c|}
\hline \multirow[t]{2}{*}{ Subgroup } & \multirow[t]{2}{*}{$\mathbf{n}$} & \multicolumn{4}{|c|}{ Improvement in low back pain intensity } & \multicolumn{4}{|c|}{ Improvement in back related functioning } \\
\hline & & Mean & $95 \% \mathrm{Cl}$ & Cohen's d & p-value & Mean & $95 \% \mathrm{Cl}$ & Cohen's d & p-value \\
\hline Overall & 476 & 0.19 & $0.03-0.34$ & 0.11 & 0.02 & -0.01 & $-0.33-0.31$ & 0.00 & 0.95 \\
\hline \multicolumn{10}{|l|}{ Age, $y r$} \\
\hline$<50$ & 164 & 0.12 & $-0.16-0.39$ & 0.06 & 0.63 & 0.21 & $-0.41-0.84$ & 0.05 & 0.25 \\
\hline $50-61$ & 154 & 0.16 & $-0.09-0.40$ & 0.10 & & 0.14 & $-0.35-0.63$ & 0.05 & \\
\hline$>61$ & 158 & 0.29 & $0.01-0.57$ & 0.16 & & -0.39 & $-0.94-0.15$ & -0.11 & \\
\hline \multicolumn{10}{|l|}{ Sex } \\
\hline Male & 127 & 0.18 & $-0.13-0.49$ & 0.10 & 0.96 & -0.20 & $-0.81-0.42$ & -0.06 & 0.49 \\
\hline Female & 349 & 0.19 & $0.01-0.37$ & 0.11 & & 0.06 & $-0.32-0.43$ & 0.02 & \\
\hline \multicolumn{10}{|l|}{ Race $^{\mathrm{a}}$} \\
\hline Black & 105 & -0.13 & $-0.46-0.19$ & -0.08 & 0.03 & -0.36 & $-1.04-0.32$ & -0.10 & 0.23 \\
\hline White & 355 & 0.28 & $0.10-0.46$ & 0.16 & & 0.11 & $-0.26-0.48$ & 0.03 & \\
\hline \multicolumn{10}{|l|}{ Ethnicity } \\
\hline Hispanic & 59 & 0.29 & $-0.11-0.69$ & 0.19 & 0.63 & -0.22 & $-1.18-0.74$ & -0.06 & 0.63 \\
\hline NonHispanic & 417 & 0.17 & $0.01-0.34$ & 0.10 & & 0.02 & $-0.32-0.36$ & 0.01 & \\
\hline \multicolumn{10}{|c|}{ Ever had work loss } \\
\hline \multicolumn{10}{|c|}{$\geq 1$ month due to } \\
\hline \multicolumn{10}{|l|}{ LBP } \\
\hline Yes & 216 & 0.20 & $-0.01-0.42$ & 0.13 & 0.85 & 0.15 & $-0.24-0.54$ & 0.05 & 0.38 \\
\hline No & 260 & 0.17 & $-0.05-0.39$ & 0.10 & & -0.14 & $-0.63-0.35$ & -0.04 & \\
\hline $\begin{array}{l}\text { Ever received } \\
\text { disability or } \\
\text { workers' } \\
\text { compensation } \\
\text { benefits due to }\end{array}$ & & & & & & & & & \\
\hline Yes & 115 & 0.41 & $0.12-0.70$ & 0.26 & 0.11 & 0.03 & $-0.55-0.60$ & 0.01 & 0.90 \\
\hline No & 361 & 0.12 & $-0.07-0.30$ & 0.07 & & -0.02 & $-0.40-0.36$ & -0.01 & \\
\hline \multicolumn{10}{|c|}{$\begin{array}{l}\text { History of herniated } \\
\text { disc }\end{array}$} \\
\hline Yes & 166 & 0.19 & $-0.06-0.44$ & 0.12 & 0.96 & 0.34 & $-0.08-0.75$ & 0.12 & 0.12 \\
\hline No & 310 & 0.18 & $-0.01-0.38$ & 0.10 & & -0.20 & $-0.63-0.24$ & -0.05 & \\
\hline \multicolumn{10}{|c|}{ History of sciatica } \\
\hline Yes & 202 & 0.12 & $-0.10-0.35$ & 0.08 & 0.49 & 0.20 & $-0.24-0.65$ & 0.06 & 0.26 \\
\hline No & 274 & 0.23 & $0.02-0.45$ & 0.13 & & -0.17 & $-0.62-0.28$ & -0.04 & \\
\hline \multicolumn{10}{|l|}{$\begin{array}{l}\text { History of } \\
\text { depression }\end{array}$} \\
\hline Yes & 246 & 0.27 & $0.07-0.47$ & 0.17 & 0.29 & 0.04 & $-0.41-0.50$ & 0.01 & 0.73 \\
\hline No & 230 & 0.10 & $-0.14-0.34$ & 0.05 & & -0.07 & $-0.52-0.38$ & -0.02 & \\
\hline \multicolumn{10}{|l|}{$\begin{array}{l}\text { Ever had LBP } \\
\text { surgery }\end{array}$} \\
\hline Yes & 87 & 0.13 & $-0.23-0.48$ & 0.08 & 0.72 & 0.28 & $-0.31-0.86$ & 0.10 & 0.41 \\
\hline No & 389 & 0.20 & $0.03-0.37$ & 0.12 & & -0.07 & $-0.45-0.30$ & -0.02 & \\
\hline \multicolumn{10}{|l|}{$\mathrm{BMI}, \mathrm{kg} / \mathrm{m}^{2}$} \\
\hline$<28.4$ & 162 & 0.19 & $-0.07-0.45$ & 0.11 & 0.80 & -0.04 & $-0.55-0.46$ & -0.01 & 0.59 \\
\hline $28.4-34.6$ & 156 & 0.25 & $-0.02-0.52$ & 0.14 & & 0.21 & $-0.39-0.81$ & 0.06 & \\
\hline$>34.6$ & 158 & 0.12 & $-0.16-0.40$ & 0.07 & & -0.20 & $-0.76-0.37$ & -0.05 & \\
\hline Pain catastroph & & & & & & & & & \\
\hline$<11$ & 161 & 0.28 & $0.00-0.56$ & 0.15 & 0.70 & 0.19 & $-0.30-0.67$ & 0.06 & 0.52 \\
\hline $11-24$ & 160 & 0.15 & $-0.11-0.41$ & 0.09 & & 0.04 & $-0.59-0.66$ & 0.01 & \\
\hline$>24$ & 155 & 0.13 & $-0.14-0.39$ & 0.08 & & -0.26 & $-0.82-0.29$ & -0.08 & \\
\hline Pain self efficac & & & & & & & & & \\
\hline$<29$ & 168 & 0.14 & $-0.10-0.37$ & 0.09 & 0.77 & -0.07 & $-0.53-0.38$ & -0.02 & 0.73 \\
\hline $29-41$ & 151 & 0.16 & $-0.12-0.44$ & 0.09 & & -0.13 & $-0.81-0.54$ & -0.03 & \\
\hline$>41$ & 157 & 0.27 & $-0.03-0.57$ & 0.14 & & 0.17 & $-0.38-0.72$ & 0.05 & \\
\hline
\end{tabular}

${ }^{*}$ Categories for age, body mass index, pain catastrophizing, and pain self efficacy were based on tercile cutpoints. Pain catastrophizing and pain self efficacy were measured with the Pain Catastrophizing Scale and Pain Self Efficacy Questionnaire, respectively. ${ }^{a}$ Only Black and White participants were included as racial subgroups, as there were too few participants in other racial categories for meaningful analysis. BMI, body mass index; $\mathrm{Cl}$, confidence interval; COVID-19, novel coronavirus 2019; LBP, low back pain. 
Table 5: Associations between utilization of nonpharmacological and pharmacological treatments and the primary clinical outcomes ( $n=476)$.*

\begin{tabular}{|c|c|c|c|c|c|c|}
\hline \multirow[t]{3}{*}{ Treatment } & \multicolumn{6}{|c|}{ Improvement in low back pain intensity } \\
\hline & \multicolumn{3}{|c|}{ Univariate models } & \multicolumn{3}{|c|}{ Multivariate model } \\
\hline & Standardized $\beta$ & $t$ & p-value & Standardized $\beta$ & $t$ & p-value \\
\hline \multicolumn{7}{|l|}{ Nonpharmacological } \\
\hline Exercise therapy & 0.052 & 1.14 & 0.25 & 0.058 & 1.19 & 0.24 \\
\hline Yoga & -0.023 & -0.50 & 0.62 & -0.048 & -0.99 & 0.32 \\
\hline Massage therapy & 0.043 & 0.93 & 0.35 & 0.036 & 0.69 & 0.49 \\
\hline Spinal manipulation & 0.023 & 0.50 & 0.62 & 0.007 & 0.13 & 0.89 \\
\hline Acupuncture & -0.003 & -0.07 & 0.95 & -0.004 & -0.08 & 0.94 \\
\hline Cognitive behavioral therapy & 0.060 & 1.31 & 0.19 & 0.067 & 1.43 & 0.15 \\
\hline \multicolumn{7}{|l|}{ Pharmacological } \\
\hline Nonsteroidal antiinflammatory drugs & -0.089 & -1.95 & 0.051 & -0.094 & -2.04 & 0.04 \\
\hline Opioids & -0.040 & -0.86 & 0.39 & -0.051 & -1.10 & 0.27 \\
\hline \multirow[t]{3}{*}{ Treatment } & \multicolumn{6}{|c|}{ Improvement in back related functioning } \\
\hline & \multicolumn{3}{|c|}{ Univariate models } & \multicolumn{3}{|c|}{ Multivariate model } \\
\hline & Standardized $\beta$ & $t$ & p-Value & Standardized $\beta$ & $t$ & p-Value \\
\hline \multicolumn{7}{|l|}{ Nonpharmacological } \\
\hline Exercise therapy & -0.003 & -0.07 & 0.94 & 0.011 & 0.23 & 0.82 \\
\hline Yoga & -0.008 & -0.17 & 0.86 & -0.012 & -0.24 & 0.81 \\
\hline Massage therapy & -0.009 & -0.19 & 0.85 & -0.002 & -0.04 & 0.97 \\
\hline Spinal manipulation & -0.018 & -0.38 & 0.70 & -0.025 & -0.50 & 0.62 \\
\hline Acupuncture & 0.020 & 0.44 & 0.66 & 0.018 & 0.38 & 0.70 \\
\hline Cognitive behavioral therapy & -0.020 & -0.43 & 0.67 & -0.018 & -0.39 & 0.70 \\
\hline \multicolumn{7}{|l|}{ Pharmacological } \\
\hline Nonsteroidal antiinflammatory drugs & -0.010 & -0.21 & 0.83 & -0.011 & -0.23 & 0.82 \\
\hline Opioids & -0.059 & -1.29 & 0.20 & -0.055 & -1.16 & 0.24 \\
\hline
\end{tabular}

*Associations were determined using linear regression models. The multivariate model included age, sex, and each of the other nonpharmacological and pharmacological treatments as independent variables.

concerns relating to virus transmission or restricted access due to lockdowns or social distancing. A marginally significant decrease in NSAID use for low back pain was also observed, although opioid use remained unchanged. Participants reported an improvement in low back pain intensity that was not considered to be clinically relevant. However, they also reported a small and clinically relevant improvement in pain interference with activities. It is unclear if the two latter findings could be explained by less demanding physical or social activities during the pandemic. The only interaction effect noted among the 13 prespecified subgroup variables analyzed for each of the primary clinical outcomes involved a racial disparity in which White participants experienced a significant improvement in low back pain intensity during the pandemic, whereas Black participants experienced a nonsignificant worsening in low back pain intensity.
Participants who were currently using a nonpharmacological treatment during their most recent quarterly encounter within the pandemic period did not report significantly different outcomes than nonusers of the treatment on either of the primary clinical outcome measures, including in the multivariate analyses that adjusted for age, sex, and use of each of the other nonpharmacological and pharmacological treatments. It is somewhat surprising that the decreased utilization of recommended nonpharmacological treatments for chronic pain did not have a greater adverse impact on the primary and secondary clinical outcomes studied; however, a possible explanation may be that participants undertook less demanding physical or social activities during pandemic lockdowns. Although emerging evidence now indicates that the severe acute respiratory syndrome coronavirus 2 (SARS-CoV-2) spike protein is analgesic in a 
nerve injury rat model [15], it is not possible to determine whether infection with the virus during the pandemic may have impacted utilization of the treatments or the clinical outcomes studied herein.

Participants who were currently using NSAIDs reported marginally significant increases in low back pain intensity during the pandemic, whereas current opioid users did not experience a significant change in low back pain intensity. It is unlikely that the increased low back pain intensity among NSAID users represents an opioid substitution effect, potentially attributable to unavailability of opioids, because reported opioid use remained stable during the pandemic. The reported decrease in NSAID use during the pandemic may reflect discontinued use by some participants because of less demanding physical or social activities, thereby selecting for more vulnerable NSAID users who continued to require chronic pain management to maintain or even increase their usual activities during the pandemic.

This study has several strengths and limitations that should be noted. It was conducted within a pain research registry involving a digital research platform that enabled remote data acquisition before and during the pandemic using a series of validated research instruments relating to chronic low back pain, including several recommended by the National Institutes of Health Task Force [9]. Historically, over $90 \%$ of participants continue to remain in the registry and provide complete data during all quarterly encounters within the first year [16]. The use of paired participant data before and during the pandemic not only controlled for potential known and unknown confounders, but also strengthened the likelihood of the pandemic being a cause of the observed findings. However, the study was limited by using only standard case report forms that did not ask participants about SARS-CoV-2 infection or other COVID-19-specific factors that may have impacted chronic pain management and clinical outcomes. For example, it is unknown to what degree the usual work or social activities of participants was curtailed by the pandemic and whether nonpharmacological or pharmacological treatments used during the pandemic were acquired during conventional treatment visits or by telemedicine or other methodologies adapted to deal with lockdowns or social distancing restrictions. Unfortunately, the registry case report forms were not designed to accommodate $a d$ hoc data needs that may arise during a pandemic. Also, this study only addressed short term changes during the initial 6 months of the pandemic. It is unclear whether different patterns of chronic pain management services and utilization will emerge as the pandemic evolves, and what impact these may have on clinical outcomes over a longer time period.

\section{Conclusions}

The utilization of nonpharmacological treatments (particularly exercise therapy, massage therapy, and spinal manipulation) and NSAIDs for low back pain decreased during the initial 6 months of the COVID-19 pandemic. Overall, participants reported improvement in low back pain intensity during this period, although the magnitude of the pain reduction was not clinically relevant. However, there was significant heterogeneity in this study finding, as Black participants reported nonsignificant worsening of low back pain intensity during the pandemic compared with the significant improvement reported by White participants. A small overall improvement in pain interference with activities was also reported; however, it is unclear whether this may have been a consequence of less frequent or intensive activities during the pandemic.

Research funding: None reported.

Author contributions: The author has accepted responsibility for the entire content of this manuscript and approved its submission.

Competing interests: None reported.

Informed consent: All study participants provided written informed consent prior to enrollment.

Ethical approval: Procedures for the registry in this study were approved by the North Texas Regional Institutional Review Board (protocol 2015-169).

\section{References}

1. Vos T, Flaxman AD, Naghavi M, Lozano R, Michaud C, Ezzati M, et al. Years lived with disability (YLDs) for 1,160 sequelae of 289 diseases and injuries 1990-2010: a systematic analysis for the Global Burden of Disease Study 2010. Lancet 2013;380: 2163-96.

2. Dowell D, Haegerich TM, Chou R. CDC guideline for prescribing opioids for chronic pain - United States, 2016. MMWR Recomm Rep (Morb Mortal Wkly Rep) 2016;65:1-49.

3. Qaseem A, Wilt TJ, McLean RM, Forciea MA, Clinical Guidelines Committee of the American College of Physicians. Noninvasive treatments for acute, subacute, and chronic low back pain: a clinical practice guideline from the American College of Physicians. Ann Intern Med 2017;166:514-30.

4. The White House. Proclamation on declaring a national emergency concerning the novel coronavirus disease (COVID-19) outbreak; 2020. Available from: https://www. whitehouse.gov/presidential-actions/proclamationdeclaring-national-emergency-concerning-novel-coronavirusdisease-covid-19-outbreak/\#: :text=Proclamation $\% 20$ on $\%$ 20 Declaring $\% 20$ a\%20National\%20Emergency $\%$ 20Concerning\%20the,Disease\%20(COVID\%2D19)\%200utb [Accessed 8 Nov 2020]. 
5. Shanthanna H, Strand NH, Provenzano DA, Lobo CA, Eldabe S, Bhatia A, et al. Caring for patients with pain during the COVID-19 pandemic: consensus recommendations from an international expert panel. Anaesthesia 2020;75:935-44.

6. Cohen SP, Baber ZB, Buvanendran A, McLean BC, Chen Y, Hooten WM, et al. Pain management best practices from multispecialty organizations during the COVID-19 pandemic and public health crises. Pain Med 2020;21:1331-46.

7. Emerick T, Alter B, Jarquin S, Brancolini S, Bernstein C, Luong K, et al. Telemedicine for chronic pain in the COVID-19 era and beyond. Pain Med 2020;21:1743-8.

8. Licciardone JC. Demographic characteristics associated with utilization of noninvasive treatments for chronic low back pain and related clinical outcomes during the COVID-19 pandemic in the United States. J Am Board Fam Med 2021;34(Suppl):1-8.

9. Deyo RA, Dworkin SF, Amtmann D, Andersson G, Borenstein D, Carragee E, et al. Report of the NIH Task Force on research standards for chronic low back pain. J Pain 2014;15:569-85.
10. Roland M, Morris R. A study of the natural history of back pain. Part I: development of a reliable and sensitive measure of disability in low-back pain. Spine 1983;8:141-4.

11. PROMIS. Adult profile instruments. Evanston, IL: Northwestern University; 2015.

12. Sullivan MJ. The pain catastrophizing scale: user manual. Montreal, QC: McGill University; 2009.

13. Nicholas MK. The pain self-efficacy questionnaire: taking pain into account. Eur J Pain 2007;11:153-63.

14. Faraone SV. Interpreting estimates of treatment effects: implications for managed care. Pharm Therapeut 2008;33: 700-11.

15. Moutal A, Martin LF, Boinon L, Gomez K, Ran D, Zhou Y, et al. SARS-CoV-2 spike protein co-opts VEGF-A/neuropilin-1 receptor signaling to induce analgesia. Pain 2021;162:243-52.

16. Licciardone JC, Pandya V. Prevalence and impact of comorbid widespread pain in adults with chronic low back pain: a registrybased study. J Am Board Fam Med 2020;33:541-8. 